\title{
Nephrotic syndrome due to preeclampsia before 20 weeks of gestation: a case report
}

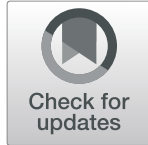

Tomo Suzuki ${ }^{1,2^{*}}$ (D), Daisuke Ichikawa', Mayumi Nakata', Shiika Watanabe ${ }^{1}$, Wei Han ${ }^{1}$, Kaori Kohatsu', Sayuri Shirai ${ }^{3}$, Naohiko Imai', Junki Koike ${ }^{4}$ and Yugo Shibagaki ${ }^{1}$

\begin{abstract}
Background: Preeclampsia (PE) refers to the development of hypertension and new-onset proteinuria or progressive organ damage (especially kidney) in a previously normotensive pregnant women after 20 weeks of gestation. Thus, new-onset nephrotic syndrome due to PE before 20 weeks of gestation seems to be rare, making its diagnosis difficult in this time period.
\end{abstract}

Case presentation: A 28-year-old woman presented with a new-onset nephrotic syndrome at 16 weeks of gestation. A high dose of oral glucocorticoids (prednisolone, $40 \mathrm{mg}$ ) was initiated for presumed glomerulonephritis since she presented with severe nephrotic syndrome before 20 weeks of gestation, however, the treatment was not effective. At 21 weeks of gestation, we confirmed that the soluble fms-like tyrosine kinase-1 (sFlt-1)/placental growth factor (PIGF) ratio was very high (sFlt-1, 13,400 pg/mL; PIGF, $21.9 \mathrm{pg}$ / $\mathrm{mL}$; serum sFIt-1/PIGF ratio 611.9). Therefore, we diagnosed nephrotic syndrome due to $P E$, and oral glucocorticoids were discontinued. After she underwent a cesarean section at 24 weeks \& 3 days, we performed a kidney biopsy. Focal segmental sclerotic lesions with epithelial cell hyperplasia and foam cells in the tubular poles were seen on light microscopy. On immunofluorescence tests, C4d staining showed linear peripheral patterns in the glomeruli. Electron microscopy revealed diffuse subendothelial edema with focal foot process effacement. The histological diagnosis was severe glomerular endotheliosis with focal segmental glomerulosclerosis. Furthermore, the histology of placenta was consistent with PE. Eight months after delivery, her proteinuria disappeared completely.

Conclusions: We not only confirmed an abnormal serum sFlt-1/PIGF ratio but also presented the histology compatible with pure PE in the kidney and placenta in a case of nephrotic syndrome before 20 weeks of gestation. The serum sFIt-1/PIGF ratio may be useful in determining the treatment strategy for atypical cases of pregnant women with nephrotic syndrome, particularly before 20 weeks of gestation.

Keywords: Nephrotic syndrome, Preeclampsia, Soluble fms-like tyrosine kinase-1, Placental growth factor

\footnotetext{
* Correspondence: t2suzuki@marianna-u.ac.jp

'Division of Nephrology and Hypertension, Department of Internal Medicine,

St. Marianna University School of Medicine, 216-8511, 2-16-1, Sugao,

Miyamae-ku, Kawasaki, Kanagawa, Japan

${ }^{2}$ Department of Nephrology, Kameda Medical Center, Chiba, Japan

Full list of author information is available at the end of the article
}

(c) The Author(s). 2020 Open Access This article is licensed under a Creative Commons Attribution 4.0 International License, which permits use, sharing, adaptation, distribution and reproduction in any medium or format, as long as you give appropriate credit to the original author(s) and the source, provide a link to the Creative Commons licence, and indicate if changes were made. The images or other third party material in this article are included in the article's Creative Commons licence, unless indicated otherwise in a credit line to the material. If material is not included in the article's Creative Commons licence and your intended use is not permitted by statutory regulation or exceeds the permitted use, you will need to obtain permission directly from the copyright holder. To view a copy of this licence, visit http://creativecommons.org/licenses/by/4.0/ The Creative Commons Public Domain Dedication waiver (http://creativecommons.org/publicdomain/zero/1.0/) applies to the data made available in this article, unless otherwise stated in a credit line to the data. 


\section{Background}

Hypertensive disorders of pregnancy (HDP) is a term used to describe increased blood pressure during pregnancy. Preeclampsia (PE) refers to the development of hypertension and new-onset proteinuria or progressive organ damage (especially kidney) in a previously normotensive pregnant women after 20 weeks of gestation. There are various clinical manifestations of the kidney in $\mathrm{PE}$, some of which are acute kidney injury, or proteinuria with or without nephrotic syndrome in PE [1]. In addition, PE has been reported to be associated with chronic kidney disease, including end stage kidney disease $[2,3]$. Consequently, the diagnosis of PE is important. However, since the PE is thought to occur after 20 weeks of gestation and the reported cases of PE with nephrotic syndrome before 20 weeks of gestation are rare [4-7], it is difficult to diagnose PE as a causal pathology for nephrotic syndrome and determine treatment strategy for these cases.

Here, we present a case of a woman with nephrotic syndrome developed before 20 weeks of gestation without abnormalities of the fetus. She did not respond to steroid, which is used for presumed glomerulonephritis and was found to have not only abnormal serum levels of soluble fms-like tyrosine kinase-1 (sFlt-1) and placental growth factor (PIGF) as markers of PE, but also the histology of the kidney which was completely compatible with PE after delivery.

\section{Case presentation}

A 28-year-old Japanese woman had infertility, with G5 P1, but not antiphospholipid syndrome. Owing to protein $\mathrm{S}$ deficiency, she was treated with aspirin $100 \mathrm{mg}$ per day and heparin therapy, which was discontinued because of a subchorionic hematoma at 12 weeks of gestation. At 16 weeks, she presented with proteinuria and edema in the lower extremities and was transferred to another hospital. A high dose of oral glucocorticoids (prednisolone, $40 \mathrm{mg}$ ) was initiated for presumed primary glomerulonephritis before 20 weeks of gestation with severe hypoalbuminemia $(1.8 \mathrm{~g} / \mathrm{dL})$ and severe proteinuria $(10 \mathrm{~g} / \mathrm{gCre})$ were suspected. In addition, $40 \mathrm{mg}$ of nifedipine per day and $750 \mathrm{mg}$ of methyldopa hydrate per day were administered for hypertension. Her condition failed to improve, and bilateral pleural effusion appeared. Therefore, she was transferred to our hospital at 21 weeks and 3 days of gestation.

Her medical history was unremarkable, except for infertility. Her birthweight was within the normal range (3260 g). Her height was $156 \mathrm{~cm}$, blood pressure was not high at $128 / 91 \mathrm{mmHg}$, and she weighed $53.3 \mathrm{~kg}$. She had remarkable edema in her lower extremities. She did not have sclerodactyly. Laboratory test results were as follows. Serum total protein and albumin levels were very low at 4.9 and $2.2 \mathrm{~g} / \mathrm{dL}$, respectively. Serum creatinine and uric acid were slightly high at 0.65 and $6.9 \mathrm{mg} / \mathrm{dL}$, respectively, owing to her gestation. Serum total cholesterol, low density lipoprotein cholesterol, and triglycerides were 510, 329, and $439 \mathrm{mg} / \mathrm{dL}$, respectively. Creactive protein was $0.37 \mathrm{mg} / \mathrm{dL}$, and urine protein content was $5.6 \mathrm{~g} /$ day, with no hematuria. Antinuclear antibody was low titer (1:40), and anti-centromere antibody was positive at $29.3 \mathrm{IU} / \mathrm{mL}$. In addition, anti-dsDNA, anti- $\beta 2$-glycoprotein I antibody, and anti-phospholipid IgG antibody, lupus anticoagulant were negative. Serum IgG, IgA, C3, and C4 levels were 131, 85, 64, and $10 \mathrm{mg} /$ $\mathrm{dL}$, respectively. Serum IgM and IgE levels were 139 and $133 \mathrm{mg} / \mathrm{dL}$, respectively. Further, protein S activity was in the normal range (95\%) in our hospital.

She met the criteria for nephrotic syndrome. However, it was difficult to diagnose primary nephrotic syndrome due to PE before 20 weeks without kidney biopsy. Therefore, we examined serum soluble fms-like tyrosine kinase-1 (sFlt-1) and placental growth factor (PlGF) levels since the ratio of sFlt-1/PlGF (>36) in pregnant women have been demonstrated as a predictor of PE [8]. The sFlt-1/PlGF ratio turned out to be very high (sFlt-1, 13,400 pg/mL; PlGF, $21.9 \mathrm{pg} / \mathrm{mL}$; serum sFlt-1/PlGF ratio 611.9), so that we diagnosed her nephrotic syndrome because of PE, and we discontinued oral glucocorticoids. We used furosemide and human albumin solution, however, her fetal growth curve was lower than 2 standard deviation after 21 weeks (Fig. 1) and, further, she had a reflux of uterine artery blood flow. Therefore, she had a cesarean section at 24 weeks 3 days. Five weeks after delivery, we performed a kidney biopsy. The core kidney tissue contained 21 glomeruli without global sclerosis. Two of the 21 glomeruli showed focal segmental sclerotic lesions, with epithelial cell hyperplasia and foam cells in the tubular poles (Fig. 2a, b). In addition, spike formations and bubbly appearances of the glomerular basement membrane were absent (Fig. 2c). In addition, hyaline arteriolosclerosis and intimal thickening in the interlobular arteries were not found (Fig. 2d).

Immunofluorescence (IF) staining demonstrated diffuse, linear, peripheral patterns of $\mathrm{C} 4 \mathrm{~d}$, slight paramesangial patterns of IgM and negative results for IgG, IgA, C3, and C1q. Electron microscopy revealed diffuse subendothelial edema without electron-dense deposits. Further, diffuse foot process effacement was not observed (Fig. 3). The histological diagnosis was severe glomerular endotheliosis with focal segmental glomerulosclerosis (FSGS) lesions. For the histology of the placenta, hemorrhagic infarction around the umbilical cord and syncytial knots were consistent with PE (Fig. 4). As shown in her whole clinical course (Fig. 5), 8 months after delivery, her proteinuria disappeared completely without anti-hypertensive agents, which was also 


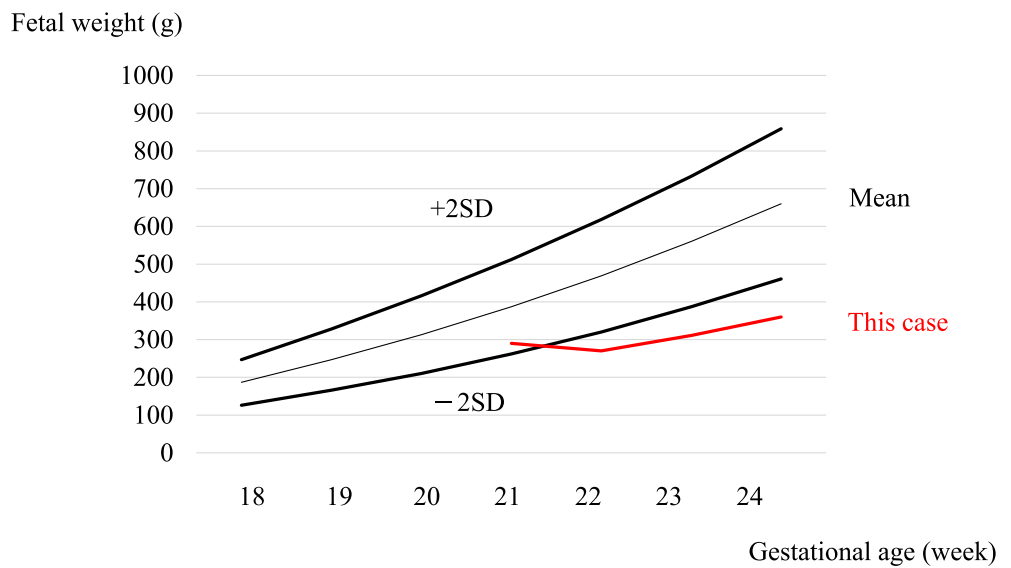

Fig. 1 Fetal growth curve from 18 weeks to 24 weeks

compatible with PE. The neonate was diagnosed with respiratory distress syndrome, rickets, and retinopathy. His weight increased from $303 \mathrm{~g}$ to $2806 \mathrm{~g} 171$ days after birth.

\section{Discussion and conclusions}

We present a case of nephrotic syndrome due to PE before 20 weeks of gestation. In addition to her clinical course compatible with PE, we confirmed PE not only by the histology of the kidney and placenta, but also by the serum markers (sFlt-1/PlGF). Further, the risk factors for PE were not clearly identified [9].

PE refers to the development of hypertension and new-onset proteinuria or progressive organ damage (especially kidney) in a previously normotensive pregnant women after 20 weeks of gestation. Therefore, it may not be an appropriate term for nephrotic syndrome before 20 weeks of gestation. Tanaka et al. reported five

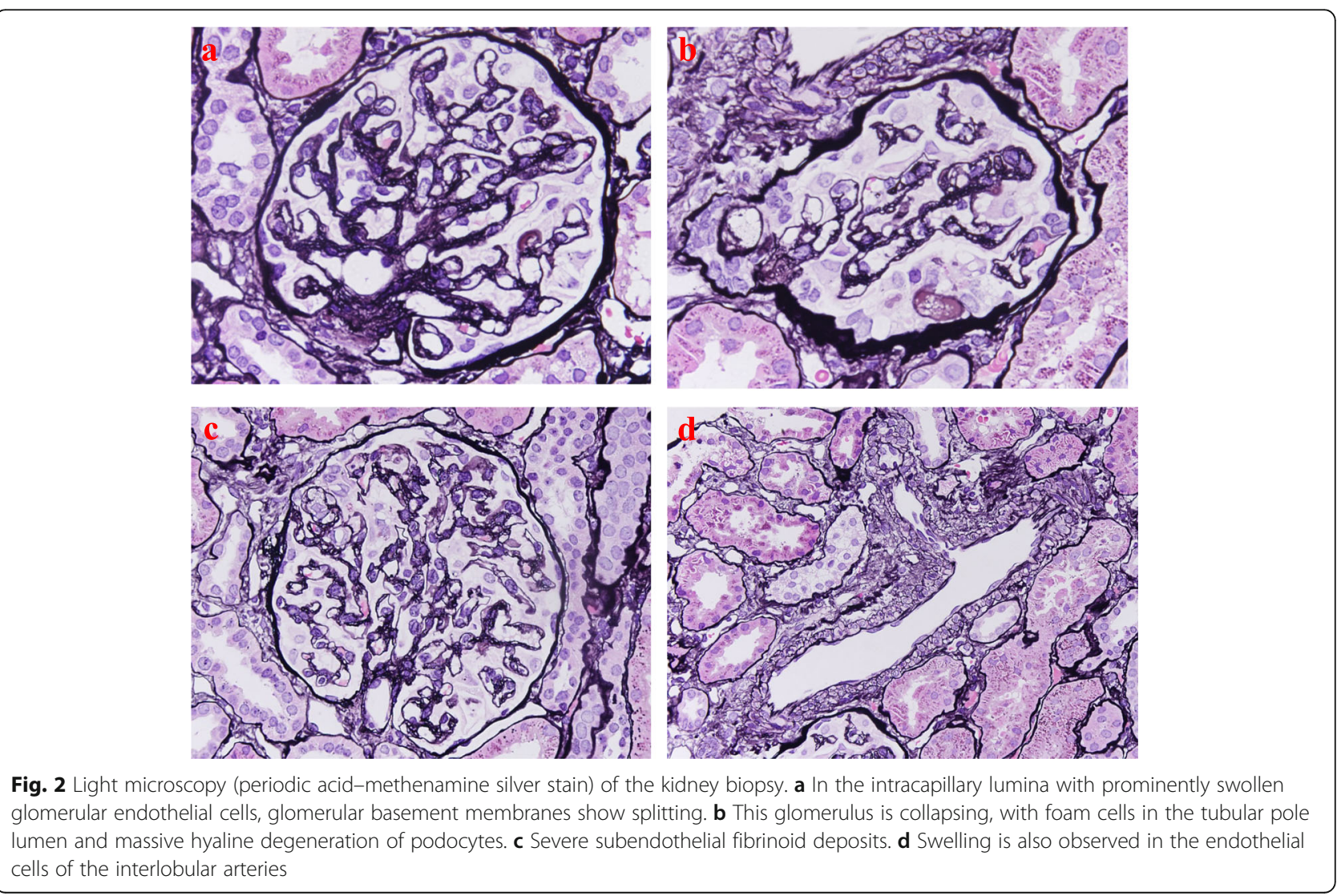



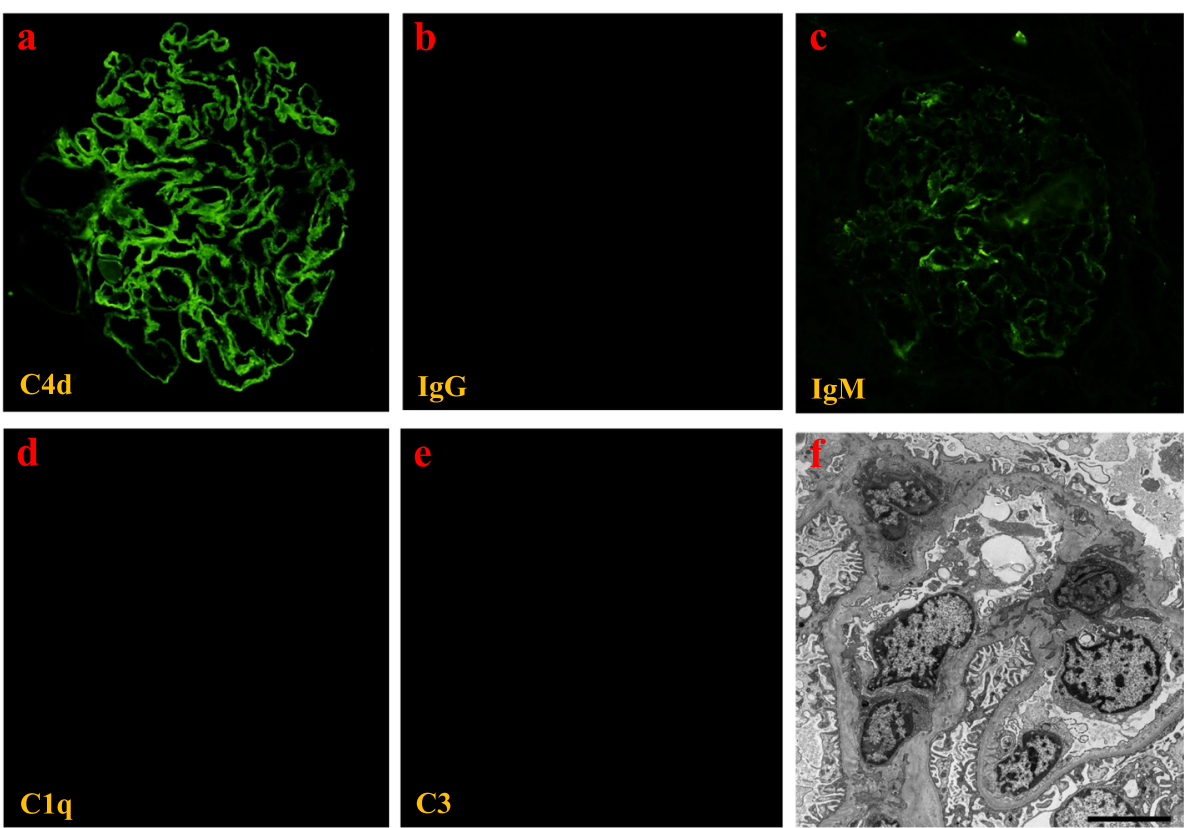

Fig. 3 Immunofluorescence results. a Image shows glomerular C4d, b IgG, c IgM, d C3 and e C1q. f Electron microscopy shows prominent glomerular endothelial swelling and no foot process effacement

cases and a literature review [7]; however, reports of nephrotic syndrome associated with pregnancy before 20 weeks are scarce. Hence, we had difficulties in diagnosing this condition. Similar to our case, Tanaka et al. treated nephrotic syndrome using glucocorticoid therapy as an empiric therapy without kidney biopsy. In spite of treatment, urinary protein excretion increased and fell to normal levels within 6 months postpartum [7].

Imasawa et al. showed pure PE with nephrotic syndrome of performing a kidney biopsy at 17 weeks of gestation [5]. In general, it is difficult to decide whether to perform a kidney biopsy on pregnant women with nephrotic syndrome. According to a systematic narrative review, kidney biopsies during pregnancy have a significantly higher risk of complications, which endanger both the mother and fetus, compared to postpartum biopsies [10]. Alternatively, kidney biopsies performed to diagnose glomerulonephritis or PE during pregnancy have led to therapeutic changes in $66 \%$ of cases [10]. Therefore, it was difficult to make differential diagnosis for primary nephrotic syndrome without kidney biopsy; PE or glomerulonephritis. Also, we could not perform kidney biopsy because of bilateral pleural effusion in addition to pregnancy. Histological diagnosis is important to determine whether to treat using glucocorticoids without kidney biopsy and interrupt pregnancy before 20 weeks of gestation. Therefore, we selected the treatment strategy based on the sFlt-1/PlGF ratio.
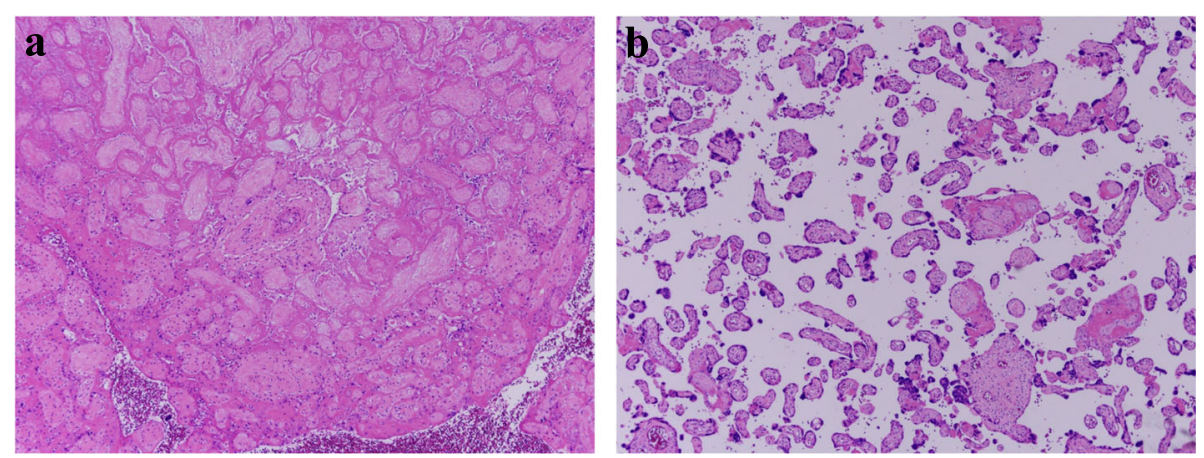

Fig. 4 Light microscopy of the placenta (periodic acid stain). a Hemorrhagic infarction is seen around the umbilical cord with low-power magnification. b Syncytial knots are seen with high-power magnification 


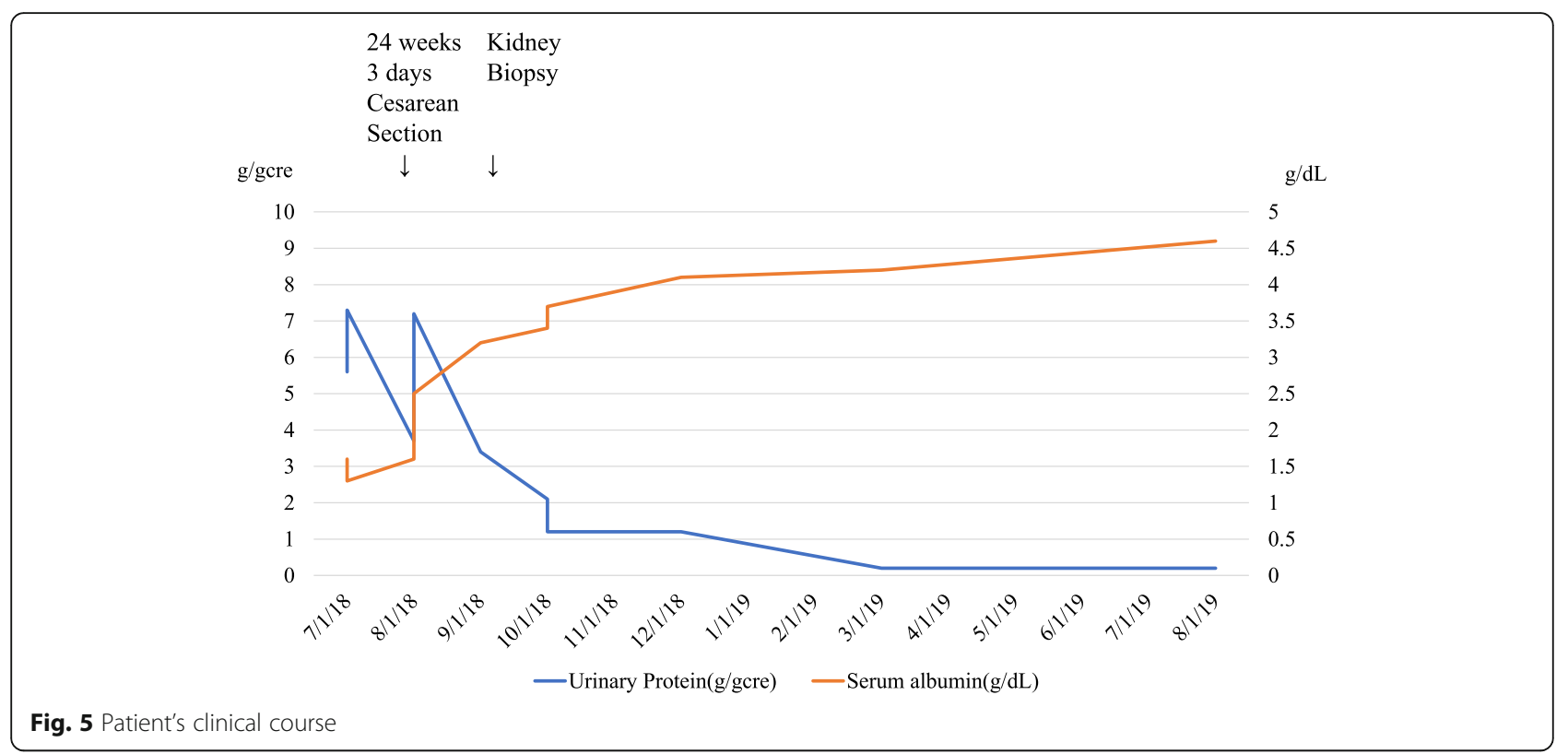

Soluble Flt-1 is known to increase owing to placental ischemia and endometrial vascular endothelial growth factor (VEGF) in PE; further, it neutralizes VEGF [11]. Soluble Flt-1 gradually increases with progression of pregnancy [8]. We confirmed her serum sFlt-1 levels to be $13,400 \mathrm{pg} / \mathrm{mL}$ and PlGF to be $21.9 \mathrm{pg} / \mathrm{mL}$ at 20 weeks of gestation, however it is difficult to evaluate the absolute serum levels of sFlt-1 and PIGF.

Histologically, the differential diagnosis is FSGS, including primary FSGS. Arteriosclerosis and glomerular hypertrophy in our case were not remarkable. In addition, low glomerular density was unclear because one kidney core included 21 glomeruli. In EM, the rate of foot process effacement was under $50 \%$. Secondary FSGS is commonly characterized by the presence of segmental foot process effacement on EM [12]. Based on the clinical data, she did not have low birthweight. Therefore, we considered that the histological diagnosis was neither primary podocyte disease nor adaptive FSGS. Further, collapsing glomerulopathy, a severe glomerular endothelial injury, often occurs in FSGS lesions [13]. Alejandra et al. reported three cases of collapsing lesions and focal segmental glomerulosclerosis during pregnancy and examined the serum sFlt-1/PlGF ratio in one out of three cases [14]. This ratio was 88.76 , and the ratio in our case was much higher than this. Therefore, we considered that the ratio was reflective of the severity in our case. Histological analyses have shown that PE is caused by glomerular endothelial and podocyte injuries [15]. Our case confirmed injuries to not only the endothelial cells, but also the foam cells, as well as segmental sclerosis. For IF, kidney biopsy in our case showed C4d deposits only, not IgG and C1q. C4d deposits may be the result of severe endothelial injury, such as antibody mediated rejection in kidney transplantation. Recently, C4d deposits are frequently seen owing to classical complement pathway activation in the kidney of preeclamptic women [16]. Considering the histology and clinical findings, our patient's nephrotic syndrome was diagnosed as pure PE.

In conclusion, we present a case of a woman with nephrotic syndrome developed before 20 weeks of gestation due to $\mathrm{PE}$, which was confirmed by typical clinical course, abnormal raio of soluble fms-like tyrosine kinase-1 (sFlt-1)/ placental growth factor (PlGF) and the histology of the kidney and placenta. The serum sFlt-1/ PIGF ratio may be very useful and significant in the diagnosis of PE in pregnant women with nephrotic syndrome, particularly before 20 weeks of gestation.

\section{Abbreviations}

EM: Electron microscopy; FSGS: Focal segmental glomerulosclerosis; IF: Immunofluorescence; PE: Preeclampsia; PIH: Pregnancy-induced hypertension; PIGF: Placental growth factor; VEGF: Vascular endothelial growth factor; sFlt-1: soluble fms-like tyrosine kinase-1

\section{Acknowledgements}

The authors would like to thank Ayako Miura-Yoshida who is affiliated with the St. Marianna University Gynecology Department, for information during the patient's pregnancy and after delivery. We would like to thank Toshiaki Monkawa and Michio Nagata who helped us in the Japan Society of Nephrology conference.

\section{Authors' contributions}

TS, NM and SW wrote the manuscript. DI and YS contributed to the review and revision of the manuscript. TS, NM, WH, KK, SS, NI and YS took clinical care of the patient. TS, SW, DI, and JK contributed histological interpretations. All authors have read and approved the final manuscript.

Funding

The authors have no financial sources to declare. 


\section{Availability of data and materials}

The datasets used and/or analyzed during the report are available from the corresponding author on reasonable request.

\section{Ethics approval and consent to participate}

Not applicable.

\section{Consent for publication}

Written informed consent for the patient's clinical details with any identifying images was obtained from the patient for publication of this Case Report. A copy of the written consent is available for review by the Editor of this journal. A copy of the written consent is available for review by the Editor of this journal.

\section{Competing interests}

The authors declare that they have no competing interests.

\section{Author details}

'Division of Nephrology and Hypertension, Department of Internal Medicine, St. Marianna University School of Medicine, 216-8511, 2-16-1, Sugao, Miyamae-ku, Kawasaki, Kanagawa, Japan. ${ }^{2}$ Department of Nephrology, Kameda Medical Center, Chiba, Japan. ${ }^{3}$ Department of Nephrology and Hypertension, St. Marianna University School of Medicine Yokohama City Seibu Hospital, Yokohama, Kanagawa, Japan. ${ }^{4}$ Department of Diagnostic Pathology, St. Marianna University School of Medicine, Kawasaki, Kanagawa, Japan.

Received: 16 January 2020 Accepted: 1 June 2020

Published online: 29 June 2020

\section{References}

1. Phipps E, Prasanna D, Brima W, Jim B. Preeclampsia: updates in pathogenesis, definitions, and guidelines. Clin J Am Soc Nephrol. 2016;11: 1102-13.

2. Filali Khattabi Z, Khattabi Z, Biolcati M, Fois A, Chatrenet A, Laroche D, Attini $R$, et al. Chronic kidney disease in preeclamptic patients: not found unless searched for-is a nephrology evaluation useful after an episode of preeclampsia? J Nephrol. 2019;32:977-87.

3. Kattah AG, Scnatebury DC, Agrawal S, Mielke MM, Rocca WA, Weaver AL, et al. Preeclampsia and ESRD: the role of shared risk factors. Am J Kidney Dis. 2017;69(4):498-505.

4. Hazra S, Waugh J, Bosio P. 'Pure' pre-eclampsia before 20 weeks of gestation: a unique entity. BJOG. 2003;110:1034-5.

5. Imasawa T, Nishiwaki T, Nishimura M, Shikama M, Matsumura R, Nagai M, et al. A case of "pure" preeclampsia with nephrotic syndrome before 15 weeks of gestation in a patient whose renal biopsy showed glomerular capillary endotheliosis. Am J Kidney Dis. 2006;48:495-501.

6. Stillman IE, Karumanchi SA. The glomerular injury of pre-eclampsia. J Am Soc Nephrol. 2007;18:2281-4.

7. Tanaka M, Tsujimoto Y, Goto K, Kumahara K, Onishi S, Iwanari S, et al. Preeclampsia before 20 weeks of gestation: a case report and review of the literature. CEN Case Rep. 2015;4:55-60.

8. Zeisler H, Llurba E, Chantraine F, Vatish M, Staff AC, Sennstrom M, et al. Predictive value of the sFlt-1:PIGF ratio in women with suspected preeclampsia. N Engl J Med. 2016;374:13-22.

9. Piccoli GB, Cabiddu G, Castetellino S, Gernone G, Santoro D, Moroni G, et al. $A$ best practice position statement on the role of the nephrologist in the prevention and follow-up of preeclampsia: the Italian study group on kidney and pregnancy. J Nephrol. 2017;30:307-17.

10. Piccoli GB, Daidola G, Attini R, Parisi S, Fassio F, Naretto C, et al. Kidney biopsy in pregnancy: evidence for counselling? A systematic narrative review. BJOG. 2013;120:412-27.

11. Fan X, Rai A, Kambham N, Sung JF, Singh N, Petitt M, et al. Endometrial VEGF induces placental sFLT1 and leads to pregnancy complications. J Clin Invest. 2014;124:4941-52

12. Sethi S, Glassock RJ, Fervenza FC. Focal segmental glomerulosclerosis: towards a better understanding for the practicing nephrologist. Nephrol Dial Transplant. 2015;30(3):375-84

13. Buob D, Decambron M, Gnemmi V, Frimat M, Hoffmann M, Azar R, et al. Collapsing glomerulopathy is common in the setting of thrombotic microangiopathy of the native kidney. Kidney Int. 2016;90:1321-31.
14. Penning M, Chua JS, van Kooten C, Zandbergen M, Muurma A, Schutte J, et al. Classical complement pathway activation in the kidneys of women with preeclampsia. Hypertension. 2015;66(1):117-25.

15. Orozco Guillén OA, Velazquez Silva Rl, Gonzalez BM, Becerra Gamba T, Gutierrez Marin A, Paredes MR, et al. Collapsing lesions and focal segmental glomerulosclerosis in pregnancy: a report of 3 cases. Am J Kidney Dis. 2019; 74:837-43.

16. Gilani SI, Anderson UD, Jayachandran M, Weissgerber TL, Zand L, White WM et al. Urinary extracellular vesicles of podocyte origin and renal injury in preeclampsia. J Am Soc Nephrol. 2017;28:3363-72.

\section{Publisher's Note}

Springer Nature remains neutral with regard to jurisdictional claims in published maps and institutional affiliations.
Ready to submit your research? Choose BMC and benefit from:

- fast, convenient online submission

- thorough peer review by experienced researchers in your field

- rapid publication on acceptance

- support for research data, including large and complex data types

- gold Open Access which fosters wider collaboration and increased citations

- maximum visibility for your research: over $100 \mathrm{M}$ website views per year

At BMC, research is always in progress.

Learn more biomedcentral.com/submissions 